\title{
Arterial blood supply variation in the anterior midline mandible: Significance to dental implantology
}

\author{
Joseph Gakonyo ${ }^{1 *}$, Fawzia Butt ${ }^{2}$, Philip Mwachaka ${ }^{2}$ and Evelyn Wagaiyu ${ }^{3}$
}

\begin{abstract}
Background: Inter-foraminal implant placement poses a risk to the sublingual artery as it enters the mandibular midline lingual foramen. Lack of consensus on the source of this artery poses a dilemma to surgeons during management of haemorrhagic episodes. Determination of the exact source of this artery is therefore pivotal.

Methods: This was a cross-sectional descriptive study involving 34 adult human cadavers. The facial and lingual arteries were followed from the external carotid artery to determine whether they terminated as the sublingual artery. Statistical significance tests were done using the Mann-Whitney $U$ test and Pearson product-moment correlation.
\end{abstract}

Results: There were $30(88.2 \%)$ males and 4 (11.8\%) females (male/female $=15: 2)$ aged between 25 and 40 years. The origin of the sublingual artery was mainly from the lingual artery (73.5\%), the submental artery (17.6\%), or an anastomotic branch from the two arteries (8.9\%). The mean distance between the mandibular midline lingual foramen (MMLF) and the inferior border of the mandible was $15.58 \mathrm{~mm}$ (range 11.03-19.62 mm). The mean thickness of the mandible at the level of the MMLF was $10.89 \mathrm{~mm}$ (range 8.00-12.91 mm). No statistically significant difference was found between the two genders with regard to the morphometric measurements.

Conclusions: The sublingual artery that enters the MMLF was found to be the sublingual artery as either a branch of the lingual artery (73.5 \%), the submental artery (17.6\%) or an anastomosis of the lingual and submental arteries (8.9\%).

Keywords: Sublingual artery; Dental implant; Mandibular midline foramen; Haemorrhage

\section{Background}

The inter-foraminal region of the human mandible is a common elective area for several dental surgery procedures due to its favourable anatomic conditions $[1,2]$. Some of the procedures done in this region include insertion of endosseous dental implants, bone harvesting from the chin, genioplasty in orthognathic surgery and placement of screws during plating in management of facial fractures [3].

There have been reported cases of near fatal upper airway obstruction due to haemorrhage following implant placement in this area $[4,5]$. Majority of them have been

\footnotetext{
* Correspondence: josegaks@gmail.com

'Department of Conservative and Prosthetic Dentistry, University of Nairobi, P.O. Box 54954-00200, Nairobi, Kenya

Full list of author information is available at the end of the article
}

attributed to transection of the sublingual artery when a misdirected drill perforates the lingual cortex and damages the blood vessel within the surrounding soft tissues [5] as it enters the mandibular midline lingual foramen (MMLF). This vessel retracts into the floor of the mouth where a haematoma forms in the sublingual and submandibular spaces leading to a compromise of the airway, by swelling and pushing of the tongue against the palate $[5,6]$.

This foramen is a constant finding and has an intraosseous part, midline mandibular lingual canal (MMLC), which contains a blood vessel that is prone to transection during routine dental implant placement [7-11]. It has been found that vessels travelling horizontal to the direction of an implant drill, but perpendicular to the

\section{空 Springer}


spin of the drill, are at the greatest risk of laceration and transection [6,7].

A higher risk of trauma exists in some situations like where the alveolar ridge is severely resorbed, or where trimming of the ridge has to be done either to reduce excess bone or to create a flat site for drilling, because this procedure brings the MMLC closer to the superior aspect of the mandible [11]. Drilling deeper into an extraction socket to obtain primary implant stability is now an acceptable procedure which increases the risk of bleeding. Some clinical protocols require inter-foraminal implant placement, which may lead to placement of an implant in the mandibular midline position [12].

There are two main sources of arterial blood supply to the anterior lingual area of the mandible: the submental and the lingual arteries. There is however lack of consensus as to the origin of the artery that enters the MMLF. Some authors have reported that it is a branch of the lingual artery and others the submental artery, while others have found that the vessel is an anastomosis of the two arteries $[2,6,7,9,13]$. The possibility of existence of anastomoses and the lack of consensus as to the source of the artery that enters the MMLF pose a dilemma of whether the submental or the lingual artery should be ligated first in the event an extra-oral approach is required to control haemorrhage [7].

There is hardly any published data on the artery that enters the MMLF. This study aimed at determining the source of the artery that enters the MMLF. It was hoped that this finding would help the surgeon to precisely ligate the feeder vessel, should there be haemorrhage during placement of an inter-foraminal dental implant.

\section{Methods}

This was a cadaveric dissection study involving 34 human adult cadavers of indigenous Kenyan descent carried out at the Department of Human Anatomy, University of Nairobi. Majority of these cadavers are unclaimed bodies in the city of Nairobi, whose demographics are hardly known. Approval to conduct the study was obtained from the Kenyatta National Hospital/University of Nairobi Ethics, Research and Standards Committee (P694/11/2014).

The procedure involved exposure of the lingual and facial arteries, beginning from the external carotid artery and following them to determine which one of them ended as the sublingual artery. This was followed by bilateral resection of the mandible at the position of the lateral incisors.

The bucco-lingual thickness of the mandible at the level of the MMLF and the distance from the inferior border of the mandible to the MMLF were measured. All photographs were taken using a HTC digital camera (Xindian, Taiwan) with dual $4 \mathrm{MP}, 2688 \times 1520$ pixels and dual-LED flash. Morphometric measurements were taken with a Pittsburgh 6-in. digital calliper (Pittsburgh, China).

Data collected were analysed using SPSS version 17 (SPSS Inc., Chicago, IL) statistical software. Probabilities that were $\leq 0.05$ were accepted as significant. Descriptive parameters were expressed as minimum, maximum and mean \pm standard deviation. The statistical significance of gender differences was determined using the MannWhitney $U$ test.

\section{Results}

A total of 34 human cadavers were dissected in this study of which $30(88.2 \%)$ were males and $4(11.8 \%)$ were females (male/female, 15:2) aged between 25 and 40 years. The linear distance between the MMLF and the inferior border of the mandible ranged from 11.03 to $19.62 \mathrm{~mm}$ (mean $=15.58 \mathrm{~mm} \pm 2.12 \mathrm{SD})$. The mesio-buccal thickness of the mandible at the level of the MMLF ranged between 8.00 and $12.91 \mathrm{~mm}$ (mean $=10.89 \mathrm{~mm} \pm 1.24 \mathrm{SD}$ ). The

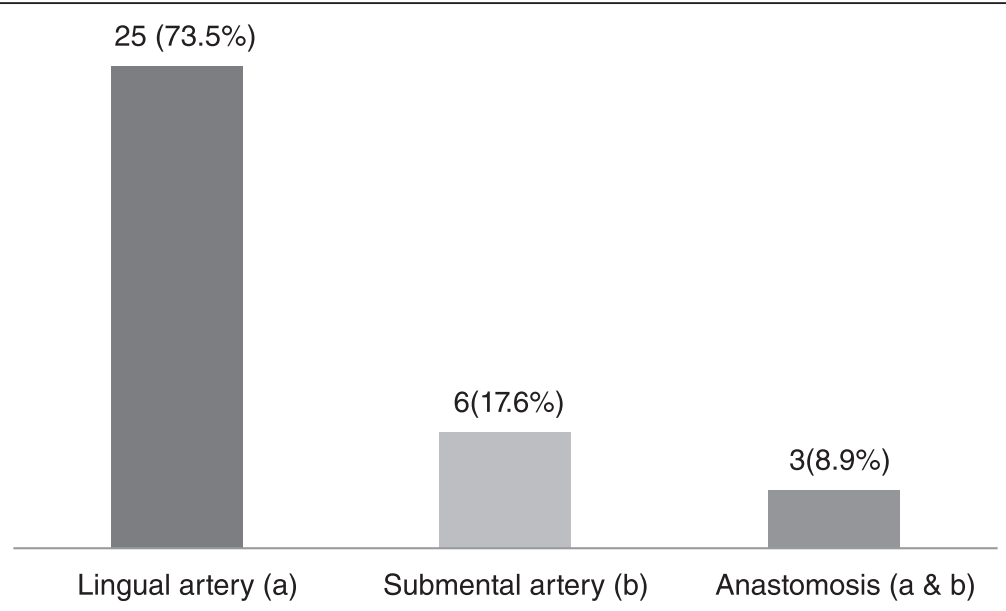

Fig. 1 Distribution of cadavers according to source of artery entering the MMLF $(n=34)$ 


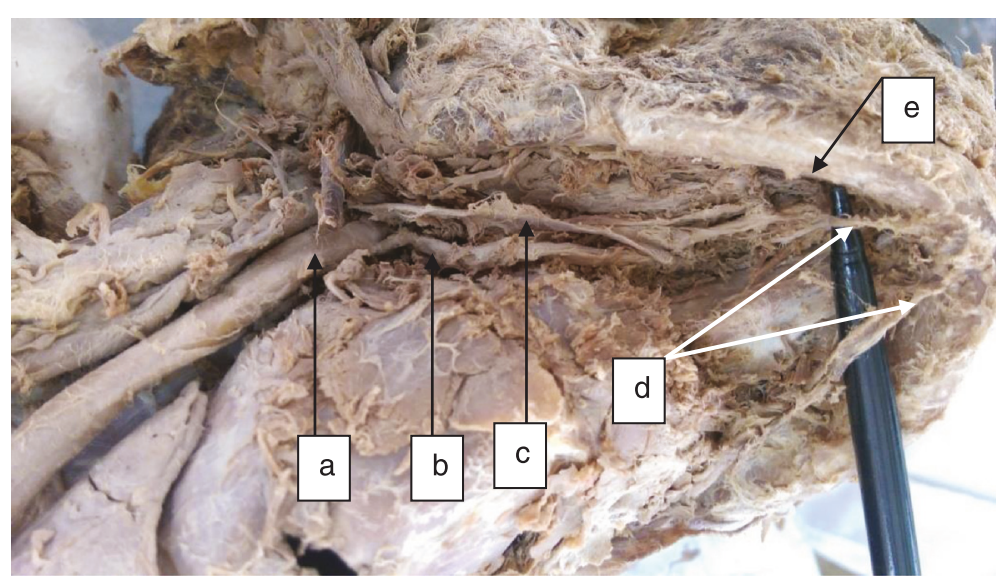

Fig. 2 Lingual artery as the origin of the sublingual artery entering the MMLF: $a$ external carotid artery, $b$ lingual artery, $c$ hypoglossal nerve, $d$ right and left sublingual arteries originating from the ipsilateral lingual arteries and $e$ inferior border of the mandible

source of the artery entering the MMLF came from either a branch of the lingual artery $(73.5 \%, n=25)$ or submental artery $(17.6 \%, n=6)$, or their anastomotic branch $(8.9 \%$, $n=3)$ (Figs. 1, 2, 3 and 4).

A Mann-Whitney $U$ test did not elicit a statistically significant difference between males and females with regard to the distance from the MMLF to the inferior border of the mandible (Table 1) or the mesio-buccal width of the mandible at the level of the MMLF (Table 2). A Pearson product-moment correlation did not elicit a statistically significant association between distance from the MMLF to the inferior border of the mandible and mesio-buccal width of the mandible at the level of the $\operatorname{MMLF}(r(1)=0.062, P=0.803$ (two-tailed)).

\section{Discussion}

The MMLF is a consistent structure through which the sublingual artery enters the mandible $[8,11]$. Perforation of the lingual plate by an implant drill poses a high risk of trauma to this vessel especially when the sublingual fossa is very pronounced because this vessel courses closely to the gland and fossa [13]. When this artery is of a significant size, it is possible for $420 \mathrm{~mL}$ of blood to escape in 30 min leading to haematoma formation in the sublingual and submandibular spaces and leading to a compromise of the airway, by swelling and pushing of the tongue against the palate $[5,6,14]$.

In a review of literature, Kalpidis et al. [7] concluded that when the haematoma is large and non-restrictive,

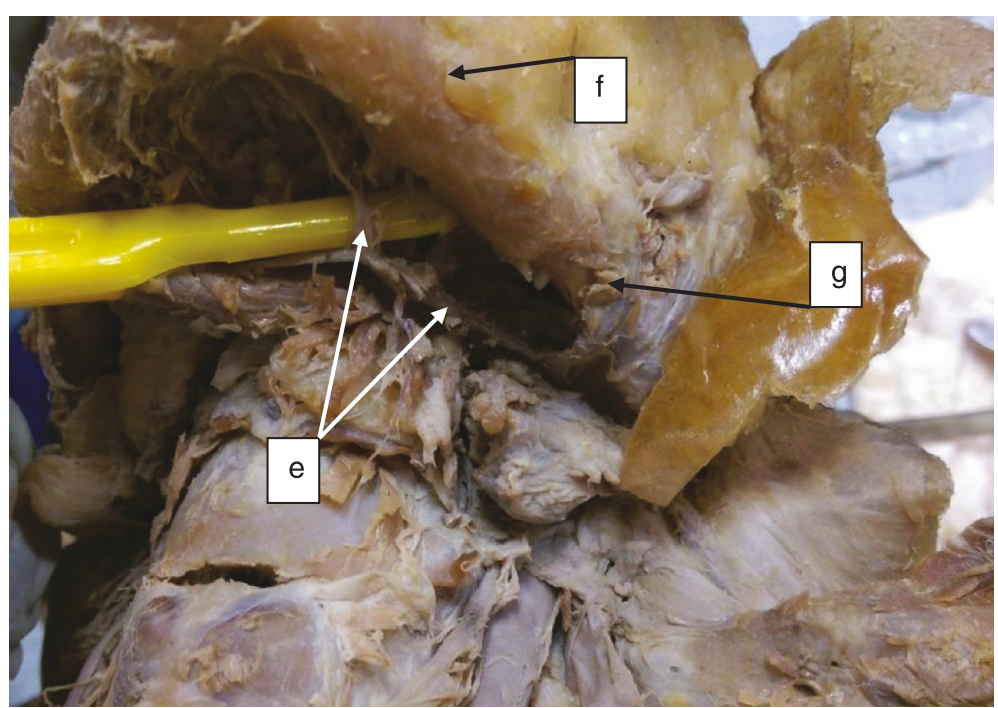

Fig. 3 Submental artery as the source of the sublingual artery entering the MMLF: e submental artery, $f$ inferior border of the mandible, and $g$ facial artery 


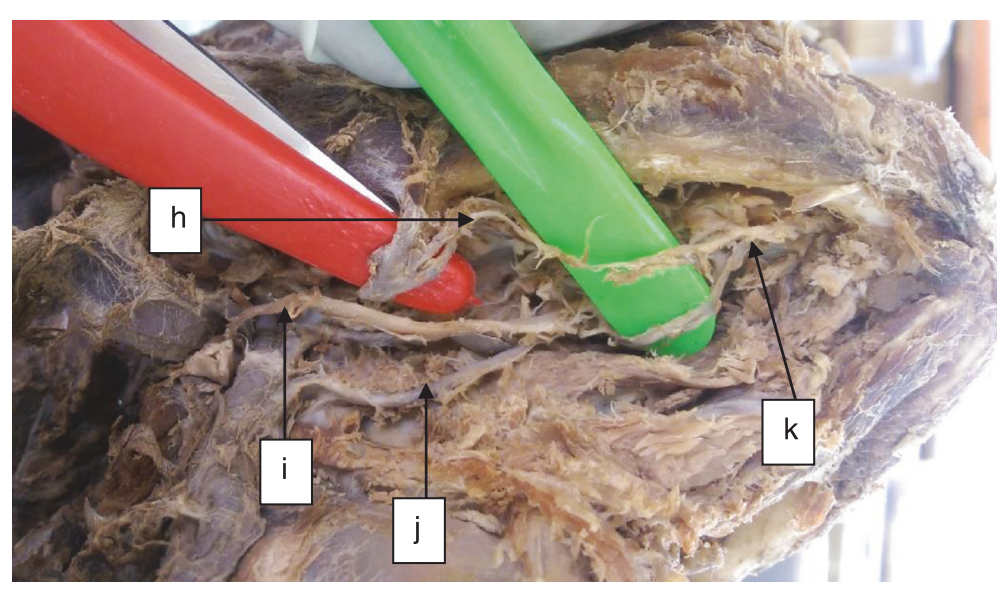

Fig. 4 Sublingual artery originating from an anastomotic branch of the lingual and submental arteries: $h$ submental artery, $i$ hypoglossal artery, $j$ lingual artery, and $k$ anastomosis of the lingual and submental arteries

extra-oral ligation of the feeder vessel should be applied. They did not establish the exact vessel that should be ligated to arrest bleeding. This was due to the differences in study findings on the prevalence of either the submental or the lingual artery as the main source of blood supply to the floor of the mouth. They thus suggested that in every case, the decision to ligate the facial or the lingual artery should be guided by the operator's judgment.

In the present study, the sublingual artery appeared to originate mainly from the lingual artery $(73.5 \%)$ which was similar to the findings of Hofschneider et al. [13] (70 \%, n=17) and Loukas et al. [6] (73 \%, n=100). Our results however contradict those of previous studies that found the sublingual artery to originate from the lingual artery in $100 \%$ of the cadavers dissected $[2,8,9,15]$. The results of these previous studies should however be interpreted with caution because a majority of them examined one to two cadavers.

In a cadaveric study by Bavitz et al. [16], it was found that the submental artery was the main arterial blood supply to the floor of the mouth (53\%). Consequently, they suggested that the submental artery should be ligated first during extra-oral ligation to control haemorrhage in the floor of the mouth. Conversely, the sublingual artery appeared to originate from the submental artery in less than a quarter $(17.6 \%)$ of the cadavers in the present study. Our results are similar to those of Loukas et al. [6] (27 \%).

The sublingual and submental arteries normally anastomose through their muscular mylohyoid branches [7].

Table 1 Distribution of distance (in $\mathrm{mm}$ ) from MMLF to the inferior border of the mandible by gender

\begin{tabular}{lllll}
\hline Gender & Number & Mean & Mann-Whitney $U$ test & $P$ \\
\hline Male & 30 & 17.97 & 46.000 & 0.454 \\
Female & 4 & 14.00 & & \\
\hline
\end{tabular}

Loukas et al. [6] only identified anastomotic patterns between sublingual and submental arteries in $40 \%$ of the dissected cadavers, with no case where the two terminate as a single sublingual artery. We found three (8.9\%) cases of an anastomotic branch of the submental and lingual artery forming a single sublingual artery just before entering the MMLF.

The distance from the MMLF to the inferior border of the mandible in our study ranged from 11.03 to $19.62 \mathrm{~mm}$ (mean $=15.58 \mathrm{~mm} \pm 2.12 \mathrm{SD}$ ) with no statistically significant difference between the two genders $(U=46.000$, $P=0.454)$. Oettle et al. [11] reported a distance ranging from 10.83 to $12.874 \mathrm{~mm}$ in a dry mandible study of both black and white South Africans. In their study, cone beam computed tomography (CBCT) was used to scan the mandibles. Their study did not find a statistically significant difference according to sex or race. Soft tissue remnants on the surface of the mandibles in our study could explain the higher morphometric measurements.

A critical buccal bone thickness of $2 \mathrm{~mm}$ is recommended to prevent vertical resorption [17]. A minimum bone thickness of $6 \mathrm{~mm}$ would be required for successful placement of a standard-sized \pm 4 -mm-diameter implant [11]. In the current study, the bucco-lingual thickness of the mandible at the level of the MMLF ranged from 8.00 to $12.91 \mathrm{~mm}$ (mean $=10.89 \mathrm{~mm} \pm 1.24 \mathrm{SD}$ ). Thus, all the cadavers in our study had adequate bone thickness needed for implant placement without perforating the lingual cortical plate and traumatizing the sublingual artery.

Table 2 Distribution of mesio-buccal width (in $\mathrm{mm}$ ) of the mandible at the level of the MMLF by gender

\begin{tabular}{lllll}
\hline Gender & Number & Mean & Mann-Whitney $U$ test & $P$ \\
\hline Male & 30 & 17.55 & 58.500 & .936 \\
Female & 4 & 17.13 & & \\
\hline
\end{tabular}


A notable limitation in our study was a lower number of female cadavers available. Most of these cadavers are unclaimed bodies from mortuaries in Kenya. Generally, there are more male unclaimed bodies than female bodies. The Mann-Whitney $U$ test was therefore used to compare the two genders.

\section{Conclusions}

Within the limitations of this study, the sublingual artery that enters the MMLF was found to be the sublingual artery as either a branch of the lingual artery $(73.5 \%)$, the submental artery $(17.6 \%)$ or an anastomosis of the lingual and submental arteries (8.9\%). We suggest that extra-oral ligation of the lingual artery should be done first followed by ligation of the submental artery (or its parent facial artery) in case of continued bleeding. Studies with a larger sample of females should be conducted to confirm the findings of this study.

\section{Competing interests}

Joseph Gakonyo, Fawzia Butt, Philip Mwachaka and Evelyn Wagaiyu declare that they have no competing interest.

\section{Authors' contributions}

EW participated in the design of the study and helped to draft the manuscript. PM participated in the study design and dissection of the cadavers and helped conduct the statistical analysis. FB participated in the study design and dissection of the cadavers and helped draft the manuscript. JG conceived the idea for the study, participated in its design and coordination, and helped draft the manuscript. All authors have read and approved the final manuscript.

\section{Acknowledgements}

The authors wish to thank the department of Human Anatomy at the University of Nairobi for enabling the conduction of this study. We thank Desmond K'Owino of the University of Nairobi for his assistance with data analysis and Dr. Antony Muthee for his assistance with typesetting. This study was financed through the University of Nairobi, Deans Committee Research Grant 2014-2015.

\section{Author details}

${ }^{1}$ Department of Conservative and Prosthetic Dentistry, University of Nairobi, P.O. Box 54954-00200, Nairobi, Kenya. ²Department of Human Anatomy, University of Nairobi, P.O. Box 25361-00603, Nairobi, Kenya. ${ }^{3}$ Department of Periodontology/Community and Preventive Dentistry, University of Nairobi, P.O. Box 30197, Nairobi, Kenya.

Received: 2 July 2015 Accepted: 20 September 2015

Published online: 30 September 2015

\section{References}

1. Longoni S, Sartori M, Braun M, Bravetti P, Lapi A, Baldoni M, et al. Lingual vascular canals of the mandible: the risk of bleeding complications during implant procedures. Implant Dent. 2007;16(2):131-8.

2. Tepper G, Hofschneider UB, Gahleitner A, Ulm C. Computed tomographic diagnosis and localization of bone canals in the mandibular interforaminal region for prevention of bleeding complications during implant surgery. Int J Oral Maxillofac Implants. 2001;16:68-72.

3. Liang X, Jacobs R, Lambrichts I. An assessment on spiral CT scan of the superior and inferior genial spinal foramina and canals. Surg Radiol Anat. 2006;28:98-104.

4. Niamtu 3rd J. Near-fatal airway obstruction after routine implant placement. Oral Surg Oral Med Oral Pathol Oral Radiol Endod. 2001;92:597-600.

5. Flanagan D. Important arterial supply of the mandible, control of an arterial hemorrhage, and report of a hemorrhagic incident. J Oral Implantol. 2003;29:165-73.
6. Loukas M, Kinsella Jr CR, Kapos T, Tubbs RS, Ramachandra S. Anatomical variation in arterial supply of the mandible with special regard to implant placement. Int J Oral Maxillofac Surg. 2008;37:367-71.

7. Kalpidis CD, Setayesh RM. Hemorrhaging associated with endosseous implant placement in the anterior mandible: a review of the literature. J Periodontol. 2004;75:631-45.

8. McDonnell D, Reza Nouri M, Todd ME. The mandibular lingual foramen: a consistent arterial foramen in the middle of the mandible. J Anat. 1994;184:363-9.

9. Tagaya A, Matsuda Y, Nakajima K, Seki K, Okano T. Assessment of the blood supply to the lingual surface of the mandible for reduction of bleeding during implant surgery. Clin Oral Implants Res. 2009;20:351-5.

10. Katakami K, Mishima A, Kuribayashi A, Shimoda S, Hamada Y, Kobayashi K. Anatomical characteristics of the mandibular lingual foramina observed on limited cone-beam CT images. Clin Oral Implants Res. 2009;20:386-90.

11. Oettle AC, Fourie J, Human-Baron R, van Zyl AW. The midline mandibular lingual canal: importance in implant surgery. Clin Implant Dent Relat Res. 2015;17(1):93-101.

12. Misch CE. The edentulous mandible: an organized approach to implantsupported overdentures. In: Misch CE, editor. Contemporary implant dentistry. 3rd ed. St. Louis: Mosby Elsevier; 2008. p. 293-313.

13. Hofschneider UB, Tepper G, Gahleitner A, Ulm C. Assessment of the blood supply to the mental region for reduction of bleeding complications during implant surgery in the interforaminal region. Int J Oral Maxillofac Implants. 1999;14:379-83.

14. Lustig JP, London D, Dor BL, Yanko R. Ultrasound identification and quantitative measurement of blood supply to the anterior part of the mandible. Oral Surg Oral Med Oral Pathol Oral Radiol Endod. 2003;96:625-9.

15. Kawai T, Sato I, Yosue T, Takamori H, Sunohara M. Anastomosis between the inferior alveolar artery branches and submental artery in human mandible. Surg Radiol Anat. 2006;28:308-10.

16. Bavitz JB, Harn SD, Homze EJ. Arterial supply to the floor of the mouth and lingual gingiva. Oral Surg Oral Med Oral Pathol. 1994;77(3):232-5.

17. Merheb J, Quirynen M, Teughels W. Critical buccal bone dimensions along implants. Periodontol. 2014;66:97-105.

\section{Submit your manuscript to a SpringerOpen ${ }^{\mathcal{D}}$ journal and benefit from:}

- Convenient online submission

- Rigorous peer review

- Immediate publication on acceptance

- Open access: articles freely available online

- High visibility within the field

- Retaining the copyright to your article

Submit your next manuscript at $>$ springeropen.com 